\title{
Role of Topotecan in Non-Small Cell Lung Cancer: A Review of Literature
}

\author{
Adarsh Vennepureddy ${ }^{\mathrm{a}, \mathrm{c}}$, Jean-Paul Atallah ${ }^{\mathrm{b}}$, Terenig Terjanian ${ }^{\mathrm{b}}$
}

\begin{abstract}
Topotecan (TPT), a chemotherapeutic agent, is a topoisomerase-I inhibitor. Topoisomerase-I is a nuclear enzyme that relieves torsion strain in DNA by opening single strand breaks which helps in DNA replication. TPT inhibits this enzyme, thus preventing DNA replication and causes cell death. TPT has demonstrated to have broad spectrum of antitumor activity in tumors like cervical, ovarian, endometrial and small cell lung cancers (SCLCs). The intravenous (IV) formulation of the drug is currently approved by the US Food and Drug Administration for the treatment of patients with SCLC and ovarian cancer at a dose of $1.5 \mathrm{mg} / \mathrm{m}^{2}$ administered daily for five consecutive days, with treatment cycles repeated every 3 weeks. TPT has shown some promising activity in the treatment of non-small cell lung cancer (NSCLC) with favorable side effect profile. Several clinical trials have been conducted with TPT in either IV or oral formulation for the treatment of NSCLC as a first or second-line treatment. Here we reviewed all the clinical trials done with TPT to date in the treatment of NSCLC both as a single-agent and combination therapy.
\end{abstract}

Keywords: Non-small cell lung cancer; Topotecan; Clinical trials; Tumor response

\section{Introduction}

Topotecan (TPT), a chemotherapeutic agent, is a topoisomerase-I inhibitor. It is a water soluble derivative of camptothecin. Topoisomerase-I is a nuclear enzyme that relieves torsion strain in DNA by opening single strand breaks which helps in DNA replication. TPT inhibits this enzyme, thus preventing

Manuscript accepted for publication October 12, 2015

aDepartment of Medicine, Staten Island University Hospital, Staten Island, NY 10305, USA

bivision of Hematology and Oncology, Staten Island University Hospital, Staten Island, NY 10305, USA

${ }^{\mathrm{c} C}$ Corresponding Author: Adarsh Vennepureddy, Staten Island University Hospital, 475 Seaview Avenue, Staten Island, NY 10305, USA.

Email: adarsh.medico@gmail.com

doi: http://dx.doi.org/10.14740/wjon950e
DNA replication and causes cell death [1-3].

TPT has demonstrated to have broad spectrum of antitumor activity in tumors like cervical, ovarian, endometrial and small cell lung cancers (SCLCs). The intravenous (IV) formulation of the drug is currently approved by the US Food and Drug Administration (FDA) for the treatment of patients with SCLC and ovarian cancer at a dose of $1.5 \mathrm{mg} / \mathrm{m}^{2}$ administered daily for five consecutive days, with treatment cycles repeated every 3 weeks. An oral formulation of TPT was also approved by the FDA in October 2007 for the treatment of relapsed SCLC [4]. TPT has shown some promising activity in the treatment of non-small cell lung cancer (NSCLC) with favorable side effect profile. However, TPT is not used as a first line of choice in the treatment of advanced NSCLC.

Lung cancer remains one of the leading causes of cancerrelated death in men and women worldwide and attributes approximately 1.37 million deaths per year worldwide. NSCLC is the most common form of lung cancer and approximately $2 / 3$ of patients with NSCLC present with advanced disease. This advanced disease state leads to limited treatment options, primarily systemic therapy [5]. Surgical resection offers the best opportunity for long-term survival and cure in patients with resectable NSCLC. The molecular characterization of tumor tissue (mutations in the EGFR, ALK, K-RAS genes) in patients with NSCLC serves as a guide to treatment both in those who present with metastatic disease and in those who relapse after primary therapy.

Combination cytotoxic chemotherapy with a platinumbased doublet is the backbone of the initial systemic treatment for patients with advanced NSCLC whose tumor does not have a driver mutation [5]. Combination chemotherapy regimens using a platinum compound (cisplatin and carboplatin) plus a second active cytotoxic agent, potentially in combination with bevacizumab, are preferred as the initial treatment for younger patients with advanced NSCLC and a good performance status (PS). For patients who are not candidates for a platinum containing regimen because of potential toxicity, regimens that may offer similar benefit based upon results of randomized trials are gemcitabine plus either docetaxel or paclitaxel or pemetrexed or vinorelbine and paclitaxel plus vinorelbine is described.

However, TPT-based combination regimens can also be used as the first-line therapy in the treatment of advanced NSCLC in patients who cannot tolerate platinum-based thera- 
Table 1. Phase I Clinical Trials of Topotecan as Combination Therapy

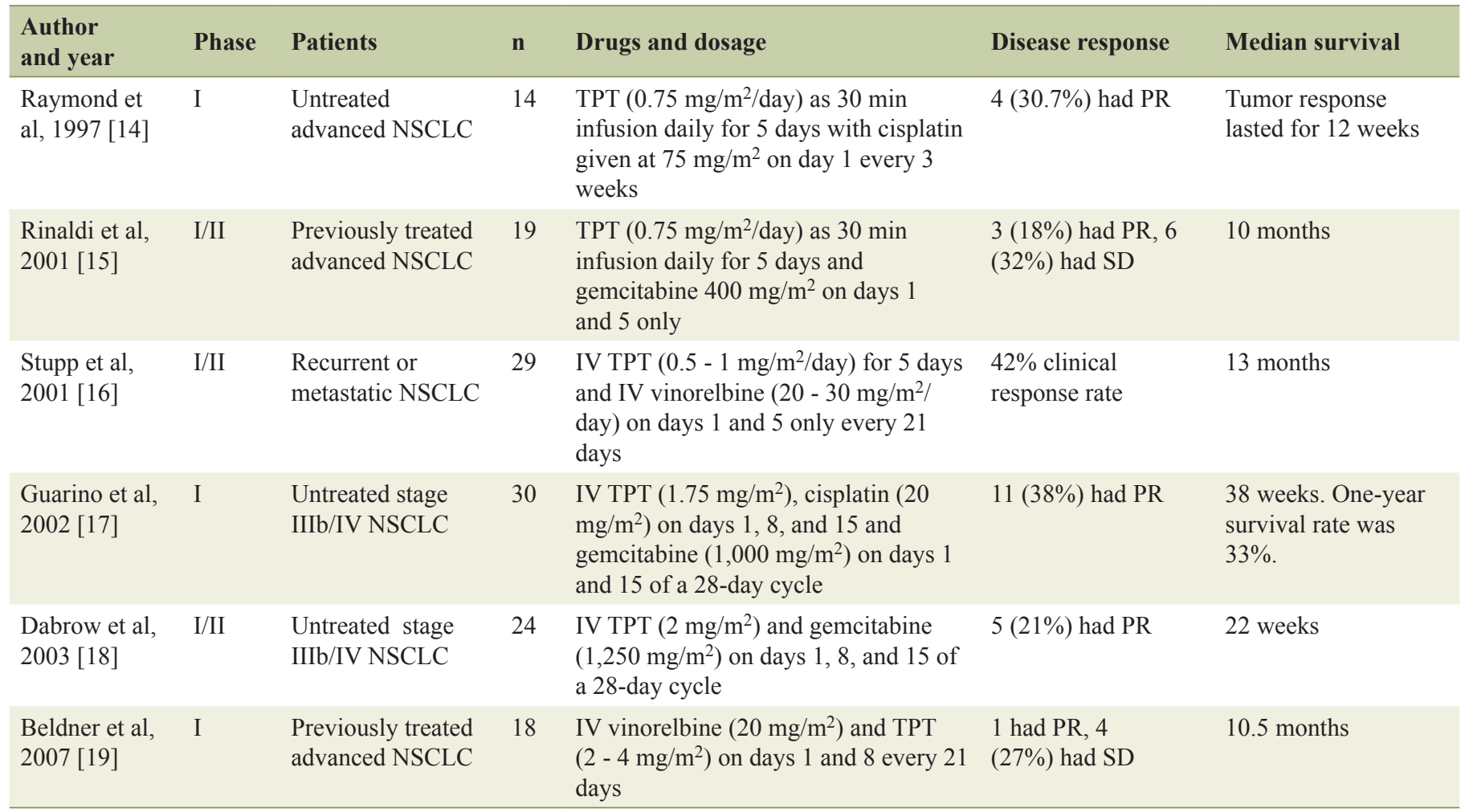

PR: partial remission; SD: stable disease; n: number of patients.

pies because of the associated toxicity, multiple co-morbidities or poor functional status of the patient. TPT-based combination regimens have demonstrated promising antitumor activities with favorable toxicity profiles in such patients. Singleagent TPT may be particularly appropriate for patients in the second-line setting, in which palliation of symptoms is an important outcome of chemotherapy.

Several clinical trials have been conducted with TPT as a single agent in either IV or oral formulation for the treatment of NSCLC as a first or second-line treatment. These trials showed a response rate of $0-25 \%$ with a median survival time of 26 - 41 weeks [6-12]. TPT in combination with other chemotherapeutic agents like gemcitabine, vinorelbine and paclitaxel had superior antitumor activity compared with studies using single-agent TPT.

Here we reviewed all the clinical trials done with TPT to date in the treatment of NSCLC both as a single-agent and combination therapy.

\section{Phase I Clinical Trial of TPT as Single-Agent Therapy}

Masuda et al [13] performed a phase I trial of TPT for the purpose of determining the maximum tolerated dose (MTD), pharmacokinetics and the dose limiting toxicity (DLT) of TPT when administered weekly to patients with advanced NSCLC. Twelve patients with stage IIIB or IV disease were treated with TPT by 30-min IV infusion on days 1,8 , and 15 every 4 weeks. The dose was escalated in $2 \mathrm{mg} / \mathrm{m}^{2}$ increments from the starting dose of $4 \mathrm{mg} / \mathrm{m}^{2}$ until the MTD was reached. After the MTD had been reached in previously treated patients, chemotherapy-naive patients were enrolled for treatment at that dose, and the dose was escalated to estimate the MTD in the treatment-naive group. This study showed that the recommended dose of TPT for phase II studies in previously untreated patients is $6 \mathrm{mg} / \mathrm{m}^{2}$ on days 1,8 , and 15 , every 28 days, and $4 \mathrm{mg} / \mathrm{m}^{2}$ appears to be a suitable dose for use in previously treated patients with this schedule. This study also showed that weekly bolus infusion of TPT appeared to be more convenient for patients with mild toxicity profile compared to the FDA approved 5-day regimen.

\section{Phase I Clinical Trials of TPT as Combination Therapy}

Raymond et al [14] in 1997 conducted a phase I study to determine the DLT of TPT in combination with cisplatin, to describe the principal toxicities, and to define the MTDs of the drugs in previously untreated patients with advanced NSCLC. The study was designed to evaluate escalated doses of TPT (starting at $0.75 \mathrm{mg} / \mathrm{m}^{2} /$ day) as a 30 -min infusion daily for five consecutive days with a fixed clinically relevant dose of $75 \mathrm{mg} / \mathrm{m}^{2}$ cisplatin given on day 1 , every 3 weeks. This study showed that both severe neutropenia and thrombocytopenia 
precluded dose escalation of TPT and cisplatin administered on this schedule. In previously untreated patients, the first TPT/cisplatin dose level $\left(0.75 / 75 \mathrm{mg} / \mathrm{m}^{2}\right)$ was associated with intolerable myelosuppression, and, therefore, the dose levels evaluated in this study cannot be recommended for subsequent phase II investigations. The high toxicity of this schedule and the recent understanding of the pharmacokinetic interaction between those drugs may encourage the investigation of the alternate sequence of cisplatin after TPT in phase II studies.

Rinaldi et al [15] conducted a phase I-II trial of TPT and gemcitabine in patients with previously treated advanced NSCLC. It was done to determine the MTD, DLT, toxicity profile, and antitumor activity of TPT and gemcitabine combination therapy. This combination was relatively well tolerated and exhibited promising antitumor activity in patients with advanced, previously treated NSCLC.

Stupp et al [16] performed a phase I/II trial in patients with recurrent or metastatic NSCLC, where the patients were treated with IV TPT and IV vinorelbine every 21-day cycles, avoiding platinum. This study concluded that the combination regimen of TPT and vinorelbine is feasible for outpatient administration and is well tolerated with less toxicity than platinum-based regimens. Preliminary response data demonstrated good antitumor activity, suggesting that this regimen could make an excellent palliative treatment for advanced NSCLC.

Guarino et al [17] designed a phase I trial to determine the optimal dose of combination TPT, cisplatin, and gemcitabine in advanced NSCLC patients. This study showed that a 28-day cycle of TPT $\left(1.75 \mathrm{mg} / \mathrm{m}^{2}\right.$ on days 1,8 , and 15$)$, cisplatin $(20$ $\mathrm{mg} / \mathrm{m}^{2}$ on days 1,8 , and 15$)$, and gemcitabine $\left(1,000 \mathrm{mg} / \mathrm{m}^{2}\right.$ on days 1 and 15) was a safe and well-tolerated outpatient treatment for advanced NSCLC.

Dabrow et al [18] performed a phase I/II trial of TPT combined with gemcitabine in patients with metastatic or unresectable NSCLC based on preclinical data showing in vitro synergy against an established lung adenocarcinoma cell line. The aim was to determine the MTD of TPT when the gemcitabine dose is held constant, as well as the DLT of this combination in NSCLC patients. The combination of gemcitabine and TPT seemed to be active against NSCLC with acceptable hematologic toxicity and minimal non-hematologic toxicity. The recommended dose for further study was $1,250 \mathrm{mg} / \mathrm{m}^{2}$ of gemcitabine (days 1,8 , and 15 ) and $2.0 \mathrm{mg} / \mathrm{m}^{2}$ of TPT (days 1 , 8 , and 15) administered every 28 days.

Beldner et al [19] conducted a phase I dose escalation study of vinorelbine and TPT combination therapy in patients with recurrent SCLC and NSCLC. The aim of this study was to evaluate the optimal dosage and the MTD of TPT and vinorelbine administered on an alternate dosing schedule. This study showed that vinorelbine and TPT administered on days 1 and 8 every 21 days was well tolerated without any DLT seen with previously investigated TPT schedules. This doublet provided a potentially active non-platinum containing doublet for the treatment of patients with advanced SCLC and NSCLC. Vinorelbine and TPT should therefore be investigated in subsequent phase II studies at a dose of $20 \mathrm{mg} / \mathrm{m}^{2}$ and $4 \mathrm{mg} / \mathrm{m}^{2}$, respectively.

In summary, phase I clinical trials done on TPT had shown good disease responses with minimal toxicity in combination with gemcitabine and vinorelbine at a dose range of $0.75-4$ $\mathrm{mg} / \mathrm{m}^{2} /$ day given as infusion for 5 days every 3 weeks or as weekly bolus infusion for 3 weeks every 28 days [15, 16, 18, 19]. TPT in combination with cisplatin is associated with high toxicity [14]. TPT as a single agent had also shown good disease response with an MTD of $6 \mathrm{mg} / \mathrm{m}^{2}$ and $4 \mathrm{mg} / \mathrm{m}^{2}$ IV on days 1 , 8 , and 15 , every 28 days in previously untreated patients and previously treated patients respectively [13]. The efficacy and safety of these doses are further studied in phase II clinical trials.

Table 1 displays all the above mentioned phase I clinical trials done on TPT in patients with advanced NSCLC as a combination therapy.

\section{Phase II Clinical Trials of TPT as Single-Agent Therapy}

Lynch et al [6] designed a phase II study to determine the clinical activity and toxicity spectrum of TPT in untreated patients with metastatic NSCLC. Toxicity included neutropenia and rash. They observed no objective clinical responses despite producing high-grade neutropenia. Phase II trials of TPT using different schedules or higher doses supported by growth factors may clarify the role of TPT in the treatment of NSCLC. However, the median survival time of 30 weeks was comparable with that obtained with combinations of agents in similar patient populations.

Perez-Soler et al [7] conducted a phase II study to assess the antitumor activity of TPT in patients with advanced NSCLC previously untreated with chemotherapy. Patients with stage IIIB or IV NSCLC with measurable disease in non-radiated fields were eligible. TPT at the dose and schedule mentioned in the above table had moderate antitumor activity in NSCLC; its activity was mostly limited to patients with squamous cell cancer. TPT was well tolerated, with myelosuppression of short duration being the most common and limiting toxicity.

Mainwaring et al [9] performed a phase II study to evaluate activity and toxicity of infusional TPT in patients with advanced NSCLC and advanced breast cancer who had not received previous chemotherapy for metastatic disease. The major toxicities were neutropenia and thrombocytopenia, with one episode of neutropenic sepsis. This study suggested that TPT delivered as a continuous IV infusion over 21 days as single-agent therapy does not appear to offer a clinical advantage over conventional 5-day schedules against advanced NSCLC and advanced breast cancer.

Kindler et al [10] conducted a phase II trial of TPT administered as a 21-day continuous IV infusion in previously untreated patients with stage IIIB and IV NSCLC. Although the major objective response rate was only $4 \%$, patients treated with TPT given as a 21-day continuous IV infusion experienced a decrease in cancer-related symptoms and a 1-year survival of $39 \%$.

Weitz et al [8] designed a randomized phase II trial of two different schedules of TPT in patients with advanced-stage NSCLC without prior cytotoxic chemotherapy. Patients were randomized to receive TPT at IV doses of $1.5 \mathrm{mg} / \mathrm{m}^{2} /$ day over $30 \mathrm{~min}$ for 5 days every 3 weeks (arm A) or $1.3 \mathrm{mg} / \mathrm{m}^{2} /$ day over $72 \mathrm{~h}$ every 4 weeks (arm B). The differences in time to progres- 
Table 2. Phase II Clinical Trials of Topotecan as Single-Agent Therapy

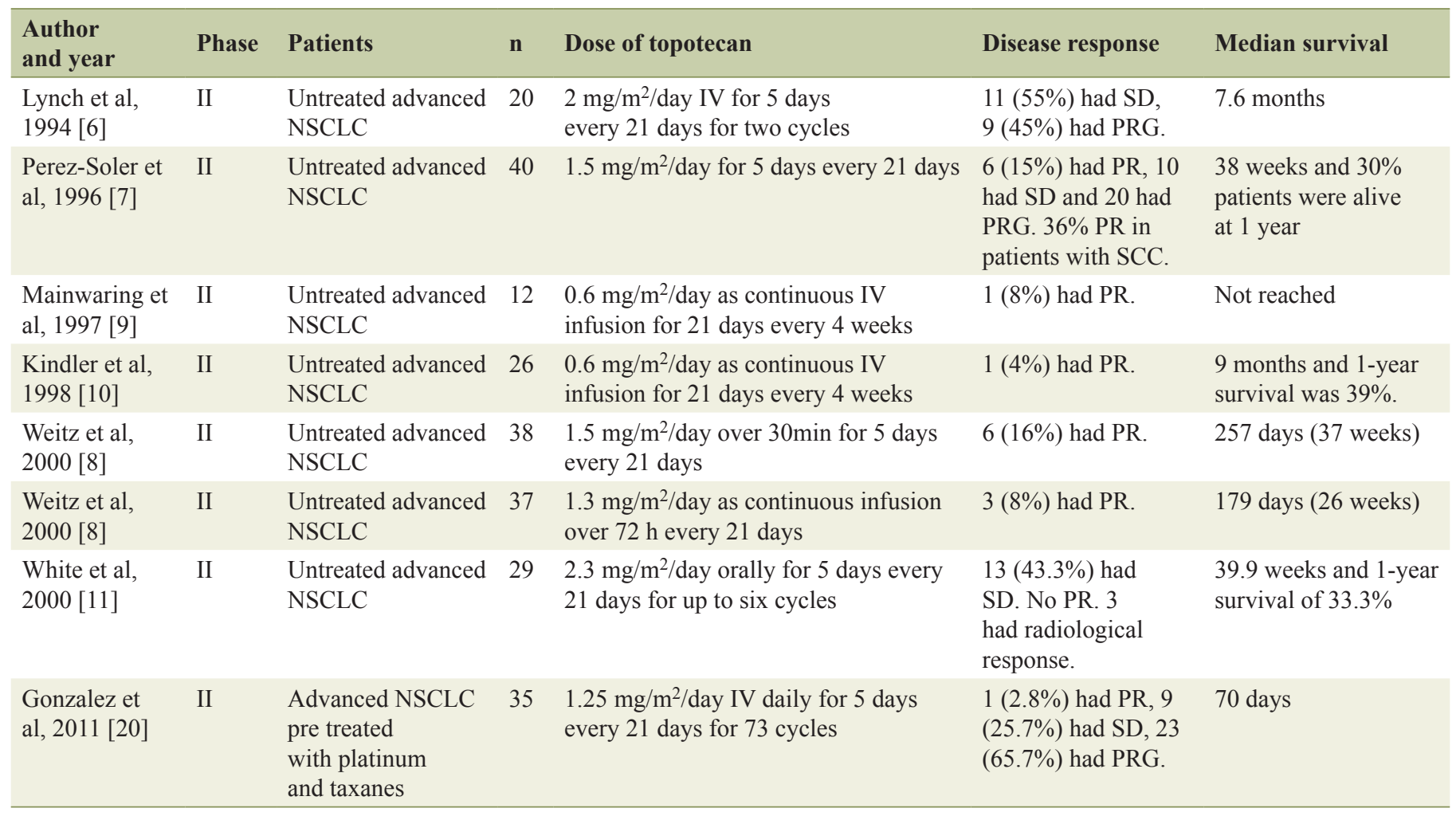

SD: stable disease; PR: partial remission; PRG: progression of disease; SCC: squamous cell cancer, n: number of patients.

sion and overall survival were not statistically significant. TPT has limited, single-agent activity in advanced NSCLC when given as $1.5 \mathrm{mg} / \mathrm{m}^{2}$ day over $30 \mathrm{~min}$ for 5 days every 3 weeks.

White et al [11] conducted a phase II trial to assess the activity of oral TPT in patients with advanced NSCLC previously untreated with chemotherapy. Oral TPT was administered at a dose of $2.3 \mathrm{mg} / \mathrm{m}^{2} /$ day for 5 days every 21 days for up to six cycles unless disease progression or unacceptable toxicity occurred. Twelve patients $(40 \%)$ experienced grade III/IV neutropenia. Five patients $(16.6 \%)$ had grade III/IV anemia. There were two episodes of grade III/IV thrombocytopenia. Although oral TPT at the applied dose and schedule showed modest activity as a single agent, almost one-half of the patients had a stable disease, and median time to progression was 12.3 weeks. The overall median survival was a promising 39.9 weeks, and useful palliation of symptoms was seen.

Gonzalez et al [20] conducted a phase II study to determine the activity of TPT given at a dose of $1.25 \mathrm{mg} / \mathrm{m}^{2} \mathrm{IV}$ for 5 days every 3 weeks in patients with advanced NSCLC pretreated with platinum and taxanes. This study showed that IV TPT at this dose and administration schedule displayed scant activity in terms of response rate in individuals with advanced NSCLC previously treated with platinum and taxanes.

In summary, phase II clinical trials done on TPT as single agent has not shown much efficacy except in the study done by Perez-Soler et al [7] which showed moderate antitumor activity at a dose of $1.5 \mathrm{mg} / \mathrm{m}^{2} /$ day IV for 5 days every 21 days in previously untreated patients. Continuous IV infusion of TPT over 21 days did not appear to offer any clinical benefit as per the studies of Mainwaring et al and Kindler et al $[9,10]$. Oral TPT at a dose of $2.3 \mathrm{mg} / \mathrm{m}^{2} /$ day for 5 days every 21 days had also shown promising antitumor activity with palliation of symptoms in the study done by White et al [11]. The effectiveness of single-agent oral TPT has been further studied in a phase III trial.

\section{Adverse effects}

The major adverse effects of TPT in phase I and II trials were hematologic characterized by anemia, leucopenia and thrombocytopenia in varying grades depending on the dose of TPT and the associated combination regimen. The non-hematologic adverse effects were characterized by lethargy, myalgia, rash, nausea, vomiting, constipation and catheter-associated infections.

Table 2 displays all the above mentioned phase II clinical trials done on TPT in patients with advanced NSCLC as a single-agent therapy.

\section{Phase II Clinical Trials of TPT as Combination Therapy}

Dowlati et al [21] designed a phase II trial of sequential topoisomerase I and II inhibition with TPT and etoposide in patients with advanced NSCLC. Hematologic toxicities included grade 
Table 3. Phase II Clinical Trials of Topotecan as Combination Therapy

\begin{tabular}{|c|c|c|c|c|c|c|}
\hline $\begin{array}{l}\text { Author } \\
\text { and year }\end{array}$ & Phase & Patients & $\mathbf{n}$ & Drugs and dosage & Disease response & Median survival \\
\hline $\begin{array}{l}\text { Dowlati et al, } \\
2001[21]\end{array}$ & II & $\begin{array}{l}\text { Untreated advanced } \\
\text { NSCLC }\end{array}$ & 19 & $\begin{array}{l}\text { TPT at } 0.85 \mathrm{mg} / \mathrm{m}^{2} / \text { day as a continuous } \\
72 \text {-h infusion from days } 1 \text { to } 3 \text { and } \\
\text { etoposide at } 100 \mathrm{mg} \text { PO twice daily for } \\
3 \text { days on days } 7-9 \text {. Total of } 55 \text { cycles. }\end{array}$ & $1 \mathrm{PR}$ and $2 \mathrm{SD}$ & $\begin{array}{l}\text { One-year survival } \\
\text { rate was } 33 \% \text {. }\end{array}$ \\
\hline $\begin{array}{l}\text { Joppert et al, } \\
2003 \text { [22] }\end{array}$ & II & $\begin{array}{l}\text { Untreated advanced } \\
\text { NSCLC }\end{array}$ & 51 & $\begin{array}{l}\text { TPT } 1 \mathrm{mg} / \mathrm{m}^{2} \text { on days } 1-5 \text {, and } \\
\text { gemcitabine } 1 \mathrm{~g} / \mathrm{m}^{2} \text { on days } 1 \text { and } 15 \\
\text { IV, every } 28 \text { days. }\end{array}$ & $\begin{array}{l}8(17 \%) \text { had PR, } \\
11(23 \%) \text { had SD }\end{array}$ & $\begin{array}{l}7.6 \text { months. One-year } \\
\text { survival rate was } \\
39 \% \text {. }\end{array}$ \\
\hline $\begin{array}{l}\text { Lorusso et al, } \\
2005 \text { [23] }\end{array}$ & II & $\begin{array}{l}\text { Previously treated } \\
\text { advanced NSCLC }\end{array}$ & 42 & $\begin{array}{l}\text { TPT }\left(1.2 \mathrm{mg} / \mathrm{m}^{2}\right) \text { plus ifosfamide } \\
\left(1,200 \mathrm{mg} / \mathrm{m}^{2}\right) \text { IV for three consecutive } \\
\text { days every } 3 \text { weeks. Total of three } \\
\text { cycles. }\end{array}$ & $\begin{array}{l}6(14.2 \%) \text { had PR, } \\
1(2.4 \%) \text { had MR, } \\
14(34 \%) \text { had SD, } \\
21(51 \%) \text { had PRG }\end{array}$ & $\begin{array}{l}26 \text { weeks. One-year } \\
\text { survival rate was } \\
14 \% \text {. }\end{array}$ \\
\hline $\begin{array}{l}\text { Stathopoulos et } \\
\text { al, } 2006[24]\end{array}$ & II & $\begin{array}{l}\text { Untreated advanced } \\
\text { NSCLC }\end{array}$ & 45 & $\begin{array}{l}\text { TPT }\left(1.75 \mathrm{mg} / \mathrm{m}^{2}\right) \text { infused over } 30 \mathrm{~min} \\
\text { and paclitaxel }\left(70 \mathrm{mg} / \mathrm{m}^{2}\right) \text { infused over } \\
90 \mathrm{~min} \text {, weekly for } 3 \text { weeks every } 28 \\
\text { days up to three cycles. }\end{array}$ & $\begin{array}{l}2(4.4 \%) \text { had } C R, 16 \\
(35.6 \%) \text { had PR, } 21 \\
(46.7 \%) \text { had SD, } 6 \\
(13.3 \%) \text { had PRG }\end{array}$ & 9 months \\
\hline $\begin{array}{l}\text { Powell et al, } \\
2013 \text { [26] }\end{array}$ & II & $\begin{array}{l}\text { Previously treated } \\
\text { advanced NSCLC }\end{array}$ & 42 & $\begin{array}{l}\text { TPT }\left(4 \mathrm{mg} / \mathrm{m}^{2}\right) \text { on days } 1,8 \text {, and } 15 \\
\text { and bevacizumab }(10 \mathrm{mg} / \mathrm{kg}) \text { on days } \\
1 \text { and } 15 \text { as IV infusion every } 28 \text { days. }\end{array}$ & $\begin{array}{l}14.3 \% \text { had PR, } \\
54.8 \% \text { had SD, } \\
28.6 \% \text { had PRG }\end{array}$ & $\begin{array}{l}\text { PFS was } 5.1 \text { months } \\
\text { and overall survival } \\
\text { was } 11.5 \text { months. }\end{array}$ \\
\hline
\end{tabular}

RCT: randomized controlled trial; ORR: overall response rate; MR: minimal remission; PFS: progression-free survival.

4 neutropenia in $7 \%$ of patients. The authors noted that the lack of efficacy in their study may have been related to the short-lived $(<24 \mathrm{~h})$ effect of topoisomerase II elevation after topoisomerase I inhibition; thus, it may be necessary to administer etoposide much earlier in a combined regimen with TPT.

Joppert et al [22] performed a phase II trial to determine the 1-year survival rate, efficacy and safety, produced by TPT and gemcitabine as first-line chemotherapy in advanced NSCLC. Grade 3 and 4 toxicities included neutropenia (53\%), anemia $(18 \%)$, thrombocytopenia $(12 \%)$, asthenia $(8 \%)$ and gastrointestinal disorders $(8 \%)$; three patients $(6 \%)$ experienced neutropenic fever. The combination of TPT/gemcitabine produced a 1-year survival similar to previous platinum-based regimens, when used as a first-line chemotherapy for advanced NSCLC. The toxicity profile was acceptable.

Lorusso et al [23] conducted a phase II trial where they used TPT plus ifosfamide in patients with advanced NSCLC. Anemia, neutropenia and thrombocytopenia were the major adverse effects. This study has shown antitumor activity with modest side effect profile and an overall disease control (PR $+\mathrm{MR}+\mathrm{SD})$. Nevertheless, the still low response rate and the shortness of median survival indicated the need for more effective second-line treatments in this disease.

Stathopoulos et al [24] conducted a phase II trial where they administered TPT and paclitaxel in patients with advanced NSCLC who were chemotherapy and radiotherapy naive. The major adverse effects were neutropenia and thrombocytopenia. This study showed that combination of TPT/paclitaxel in a weekly administration rendered a $40 \%$ response rate, with very low toxicity in stages IIIA, IIIB and IV NSCLC patients.

Jones et al [25] performed a randomized phase II trial to evaluate the efficacy of oral TPT compared with IV docetaxel in the second-line treatment of patients with NSCLC. Thirtynine patients received 138 cycles of TPT. The overall response rate (ORR) was $8 \%$, median time to progression (TTP) was 1.6 months, median survival was 8.4 months, and the 1- and 2-year survival rates were $36 \%$ and $13 \%$, respectively, for patients receiving TPT. Oral TPT appeared to be active and well tolerated when administered as a fixed dose daily for 5 of every 7 days for 2 weeks every 21 days and might provide another treatment alternative for patients with advanced-stage NSCLC.

Powell et al [26] designed a phase II study to evaluate whether TPT in combination with bevacizumab improved progression-free survival (PFS) in patients with advanced, refractory NSCLC in a second-line setting. This study proved that bevacizumab in combination with TPT as a salvage therapy for metastatic NSCLC was well tolerated and worthy of further investigation.

In summary, phase II clinical trials done on TPT as combination therapy at the above mentioned doses had shown good antitumor activity in combination with gemcitabine, paclitaxel and bevacizumab with acceptable toxicity in previously untreated patients $[22,24,26]$. However, it has no benefit when combined with etoposide and ifosfamide [21, 23]. Oral TPT had also shown to have promising antitumor activity and well tolerated as a second-line treatment in a study done by Jones 
et al [25].

Table 3 displays all the above mentioned phase II clinical trials done on TPT in patients with advanced NSCLC as a combination therapy.

\section{TPT in Combination With Radiotherapy}

Graham et al [27] designed a dose escalation clinical study with TPT and concurrent standard dose thoracic irradiation to assess its feasibility and toxicity in the treatment of patients with locally advanced, inoperable NSCLC. Twelve patients were entered in a prospective dose escalation trial and assigned to receive concurrent thoracic radiotherapy and TPT. The thoracic irradiation total tumor dose was 60 Gy in 30 fractions. Initial fields were to encompass the gross disease plus the mediastinum. TPT was delivered by bolus injection days 1 through 5 , and days 22 through 26 , beginning on the same day as the radiation therapy. The initial dose level was $0.5 \mathrm{mg} / \mathrm{m}^{2}$. Two additional dose levels of $0.75 \mathrm{mg} / \mathrm{m}^{2}$ and $1.0 \mathrm{mg} / \mathrm{m}^{2}$ were tested. At a follow-up of $12-24$ months, two patients are alive and free of disease, three patients are alive with disease and the remaining seven patients died from the disease. This study showed that combination of TPT and thoracic radiotherapy for NSCLC, in the manner given by this protocol, could be safely given at a dose level of only $0.5 \mathrm{mg} / \mathrm{m}^{2}$ days 1 to 5 and 22 to 26 with 60 Gy of external beam radiotherapy. Higher doses of TPT were associated with high hematologic and gastrointestinal toxicity.

Patel et al [28] conducted a prospective phase II study of induction carboplatin and vinorelbine followed by concomitant TPT and accelerated radiotherapy (ART) in patients with locally advanced/unresectable NSCLC. Thirty-five patients received induction carboplatin on days 1 and 22 , and vinorelbine $\left(25 \mathrm{mg} / \mathrm{m}^{2}\right)$ on days $1,8,22$, and 29 . During the concurrent chemoradiation, patients received IV TPT $\left(0.5 \mathrm{mg} / \mathrm{m}^{2}\right)$ on days 43 to 47 , days 57 to 61 , and days 71 to 75 before the morning radiotherapy (RT) fraction. RT was administered in an accelerated fashion at 2 Gy per fraction, twice daily for five consecutive days, every other week, to a cumulative dose of 60 Gy during a 5-week period. ORR was $71 \%$ (14\% complete response, $57 \%$ partial response). Six of 35 (17\%) patients had stable disease. Four (11\%) patients progressed during treatment. The median survival was 17.9 months. This combined-modality regimen yielded encouraging overall survival rates, with no severe esophagitis. Using four-dimensional RT treatment planning, they planned to further evaluate altered fractionation RT and chemotherapy for this group of patients.

Seung et al [29] performed a phase II trial of combined modality therapy with concurrent TPT plus RT followed by consolidation chemotherapy for unresectable stage III and selected stage IV NSCLC. Twenty patients were treated with infusion TPT $0.4 \mathrm{mg} / \mathrm{m}^{2} /$ day with three-dimensional conformal RT to 63 Gy both delivered Monday through Friday for 7 weeks. Patients without progression underwent consolidation chemotherapy with etoposide and a platinum agent for one cycle followed by two cycles of docetaxel. Eighteen patients had a partial response and one stable disease after induction chem- oradiotherapy. The 3-year overall survival rate was 32\% (median, 18 months). The local and distant PFS rates were $30 \%$ (median, 21 months) and 58\% (median, not reached), respectively. Grade 3 hematologic toxicity was the major adverse effect. Continuous infusion TPT with RT was well tolerated and active in the treatment of poor-risk patients with unresectable stage III NSCLC.

In summary, studies done on TPT in combination with RT in patients with locally advanced stage III NSCLC shown to have mild improvement in survival rate with acceptable toxicity profile. However, further studies need to be done on this combination to prove the efficacy for its use in clinical practice.

\section{Phase III Clinical Trials of TPT}

Ramlau et al [12] conducted a phase III study comparing oral TPT versus IV docetaxel in patients with previously treated NSCLC. Patients with stage III or IV NSCLC, PS $\leq 2$, who had received only one prior chemotherapy regimen, were randomly assigned to treatment with oral TPT $2.3 \mathrm{mg} / \mathrm{m}^{2} /$ day on days 1 to 5 or IV docetaxel $75 \mathrm{mg} / \mathrm{m}^{2}$ day 1 every 21 days. A total of 829 patients were randomly assigned. In intent-totreat analysis, 1 -year survival rates were $25.1 \%$ with TPT and $28.7 \%$ with docetaxel. Median survival was 27.9 weeks with TPT and 30.7 weeks with docetaxel. Although not statistically significant (log-rank $\mathrm{P}=0.057)$, the higher survival rate with docetaxel was maintained across the entire treatment period. The median time to progression was 11.3 weeks with TPT versus 13.1 weeks with docetaxel. Grade 3 neutropenia occurred more frequently with docetaxel, grade 3 anemia and thrombocytopenia occurred more frequently with TPT. Oral TPT provided activity in the treatment of relapsed, locally advanced, unresectable NSCLC. Both regimens were well tolerated with differing safety profiles. TPT may provide an option for patients who desire an orally available treatment after relapse.

In summary, single-agent oral TPT at a dose of $2.3 \mathrm{mg} /$ $\mathrm{m}^{2} /$ day for 5 days every 21 days can be used as a second-line agent in patients with relapsed advanced NSCLC who desire oral therapy and where palliation of symptoms is desired. This is proven based on the trials done by Ramlau et al [12], Jones et al [25] and White et al [11].

\section{Conclusion and Approach to Therapy}

Based on the clinical trials described above, TPT has demonstrated encouraging results in the treatment of NSCLC, a disease well known for its resistance to chemotherapy. Although ORRs with single-agent TPT have been relatively low in some studies, stable disease rates, when reported, were frequently high. As advanced NSCLC is a kind of disease where cure is not possible, delays in disease progression are desirable especially if toxicities are manageable. Therefore, single-agent TPT may be appropriate in the second-line setting.

TPT in combination with other antitumor agents has demonstrated superior antitumor activity compared with single 
agent. Some encouraging responses were obtained when IV TPT was combined with either gemcitabine or paclitaxel or bevacizumab or vinorelbine, with manageable toxicities at doses mentioned above in the clinical trials. In contrast, TPT in combination with etoposide or ifosfamide is associated with less antitumor activity and more adverse effects. The ideal regimen combining TPT and other agents has yet to be defined.

In conclusion, IV TPT in combination with other agents can be recommended as a first-line therapy for patients with advanced NSCLC who cannot tolerate standard platinumbased first-line treatments because of the associated toxicities, multiple co-morbid conditions or poor functional status. TPT has demonstrated response rates equivalent to those of standard therapy with manageable non-hematologic and hematologic toxicity when used as a combination therapy with other agents. TPT as a maintenance single agent in either oral or IV formulation can be used as a second-line therapy for patients who had progressed/relapsed or could not tolerate the standard therapies and where palliation of symptoms is desired.

\section{Conflict of Interest}

None.

\section{References}

1. Chen AY, Liu LF. DNA topoisomerases: essential enzymes and lethal targets. Annu Rev Pharmacol Toxicol. 1994;34:191-218.

2. Hsiang YH, Lihou MG, Liu LF. Arrest of replication forks by drug-stabilized topoisomerase I-DNA cleavable complexes as a mechanism of cell killing by camptothecin. Cancer Res. 1989;49(18):5077-5082.

3. Liu LF, Desai SD, Li TK, Mao Y, Sun M, Sim SP. Mechanism of action of camptothecin. Ann N Y Acad Sci. 2000;922:1-10.

4. Burris HA, 3rd, Infante JR, Jewell RC, Spigel DR, Greco FA, Thompson DS, Jones SF. A phase I study of weekly topotecan in combination with pemetrexed in patients with advanced malignancies. Oncologist. 2010;15(9):954-960.

5. Dearing KR, Sangal A, Weiss GJ. Maintaining clarity: Review of maintenance therapy in non-small cell lung cancer. World J Clin Oncol. 2014;5(2):103-113.

6. Lynch TJ, Jr., Kalish L, Strauss G, Elias A, Skarin A, Shulman LN, Posner M, et al. Phase II study of topotecan in metastatic non-small-cell lung cancer. J Clin Oncol. 1994;12(2):347-352.

7. Perez-Soler R, Fossella FV, Glisson BS, Lee JS, Murphy WK, Shin DM, Kemp BL, et al. Phase II study of topotecan in patients with advanced non-small-cell lung cancer previously untreated with chemotherapy. J Clin Oncol. 1996;14(2):503-513.

8. Weitz JJ, Marschke RF, Jr., Sloan JA, Grill JP, Jett JR, Knost JA, Hatfield AK, et al. A randomized phase II trial of two schedules of topotecan for the treatment of advanced stage non-small cell lung cancer. Lung Cancer. 2000;28(2):157-162.
9. Mainwaring PN, Nicolson MC, Hickish T, Penson R, Joel S, Slevin M, Smith IE. Continuous infusional topotecan in advanced breast and non-small-cell lung cancer: no evidence of increased efficacy. Br J Cancer. 1997;76(12):1636-1639.

10. Kindler HL, Kris MG, Smith IE, Miller VA, Grant SC, Krebs JB, Ross GA, et al. Phase II trial of topotecan administered as a 21-day continuous infusion in previously untreated patients with stage IIIB and IV non-small-cell lung cancer. Am J Clin Oncol. 1998;21(5):438-441.

11. White SC, Cheeseman S, Thatcher N, Anderson H, Carrington B, Hearn S, Ross G, et al. Phase II study of oral topotecan in advanced non-small cell lung cancer. Clin Cancer Res. 2000;6(3):868-873.

12. Ramlau R, Gervais R, Krzakowski M, von Pawel J, Kaukel E, Abratt RP, Dharan B, et al. Phase III study comparing oral topotecan to intravenous docetaxel in patients with pretreated advanced non-small-cell lung cancer. J Clin Oncol. 2006;24(18):2800-2807.

13. Masuda N, Matsui K, Negoro S, Takeda K, Kudoh S, Nakagawa K, Mukaiyama A, et al. Phase I and pharmacologic study of weekly bolus topotecan for advanced non-smallcell lung cancer. Clin Lung Cancer. 2010;11(4):271-279.

14. Raymond E, Burris HA, Rowinsky EK, Eckardt JR, Rodriguez $\mathrm{G}$, Smith $\mathrm{L}$, Weiss $\mathrm{G}$, et al. Phase I study of daily times five topotecan and single injection of cisplatin in patients with previously untreated non-small-cell lung carcinoma. Ann Oncol. 1997;8(10):1003-1008.

15. Rinaldi D, Lormand N, Brierre J, Cole J, Barnes B, Fontenot F, Buller E, et al. A phase I-II trial of topotecan and gemcitabine in patients with previously treated, advanced non-small cell lung cancer (LOA-3). Cancer Invest. 2001;19(5):467-474.

16. Stupp R, Bodmer A, Duvoisin B, Bauer J, Perey L, Bakr $\mathrm{M}$, Ketterer N, et al. Is cisplatin required for the treatment of non-small-cell lung cancer? Experience and preliminary results of a phase I/II trial with topotecan and vinorelbine. Oncology. 2001;61(Suppl 1):35-41.

17. Guarino MJ, Schneider CJ, Grubbs SS, Biggs DD, Himelstein AL, Hogaboom K, Tilak S. A dose-escalation study of weekly topotecan, cisplatin, and gemcitabine front-line therapy in patients with inoperable non-small cell lung cancer. Oncologist. 2002;7(6):509-515.

18. Dabrow MB, Francesco MR, Gilman PB, Cantor R, Rose L, Meyer TJ. Combined therapy with topotecan and gemcitabine in patients with inoperable or metastatic nonsmall cell lung cancer. Cancer Invest. 2003;21(4):517525.

19. Beldner MA, Sherman CA, Green MR, Garrett-Mayer E, Chaudhary U, Meyer ML, Kraft AS, et al. Phase I dose escalation study of vinorelbine and topotecan combination chemotherapy in patients with recurrent lung cancer. BMC Cancer. 2007; 7:231.

20. Gonzalez EE, Villanueva N, Fra J, Berros JP, Jimenez P, Luque M, Muniz I, et al. Activity of topotecan given intravenously for 5 days every three weeks in patients with advanced non-small cell lung cancer pretreated with platinum and taxanes: a phase II study. Invest New Drugs. 2011;29(6):1459-1464. 
21. Dowlati A, Levitan N, Gordon NH, Hoppel CL, Gosky DM, Remick SC, Ingalls ST, et al. Phase II and pharmacokinetic/pharmacodynamic trial of sequential topoisomerase I and II inhibition with topotecan and etoposide in advanced non-small-cell lung cancer. Cancer Chemother Pharmacol. 2001;47(2):141-148.

22. Joppert MG, Garfield DH, Gregurich MA, Nemunaitis JJ, Marsland TA, Khandelwal P, Asmar L. A phase II multicenter study of combined topotecan and gemcitabine as first line chemotherapy for advanced non-small cell lung cancer. Lung Cancer. 2003;39(2):215-219.

23. Lorusso V, Gebbia V, Spada M, Guida M, Cassano G, Brunetti C, Germano D, et al. Topotecan plus ifosfamide in patients with platinum refractory advanced/metastatic non-small cell lung cancer: a phase II trial. Oncol Rep. 2005;14(6):1547-1551.

24. Stathopoulos GP, Katis C, Tsavdaridis D, Dimitroulis J, Karaindros D, Stathopoulos J, Dimou E. Front-line paclitaxel and topotecan chemotherapy in advanced or metastatic non-small-cell lung cancer: a phase II trial. Cancer Chemother Pharmacol. 2006;58(4):555-560.

25. Jones S, Thompson D, Barton J, Patton J, Shipley D, Greco FA, Spigel D, et al. A randomized phase II trial of oral topotecan versus docetaxel in the second-line treatment of non-small-cell lung cancer. Clin Lung Cancer. 2008;9(3):154-159.

26. Powell SF, Beitinjaneh A, Tessema M, Bliss RL, Kratzke RA, Leach J, Dudek AZ. Phase II study of topotecan and bevacizumab in advanced, refractory non--small-cell lung cancer. Clin Lung Cancer. 2013;14(5):495-501.

27. Graham MV, Jahanzeb M, Dresler CM, Cooper JD, Emami B, Mortimer JE. Results of a trial with topotecan dose escalation and concurrent thoracic radiation therapy for locally advanced, inoperable nonsmall cell lung cancer. Int J Radiat Oncol Biol Phys. 1996;36(5):1215-1220.

28. Patel SH, Ajlouni M, Chapman R, Lu M, Movsas B, Kim JH. A prospective phase II study of induction carboplatin and vinorelbine followed by concomitant topotecan and accelerated radiotherapy (ART) in locally advanced non-small cell lung cancer (NSCLC). J Thorac Oncol. 2007;2(9):831-837.

29. Seung SK, Ross HJ. Phase II trial of combined modality therapy with concurrent topotecan plus radiotherapy followed by consolidation chemotherapy for unresectable stage III and selected stage IV non-small-lung cancer. Int J Radiat Oncol Biol Phys. 2009;73(3):802-809. 